OPEN ACCESS

Edited by:

Haigang Ren,

Soochow University, China

Reviewed by:

Yongjun Wang,

Nantong University, China

Igor Jakovcevski,

Universität Witten/Herdecke,

Germany

John R. Henley,

Mayo Clinic, United States

${ }^{*}$ Correspondence:

Florence E. Perrin

florence.perrin@inserm.fr;

florence.perrin@umontpellier.fr

Received: 02 September 2021

Accepted: 29 October 2021

Published: 26 November 2021

Citation:

Perez J-C, Gerber YN and Perrin FE (2021) Dynamic Diversity of Glial Response Among Species

in Spinal Cord Injury.

Front. Aging Neurosci. 13:769548.

doi: 10.3389/fnagi.2021.769548

\section{Dynamic Diversity of Glial Response Among Species in Spinal Cord Injury}

\author{
Jean-Christophe Perez ${ }^{1}$, Yannick N. Gerber ${ }^{1}$ and Florence E. Perrin ${ }^{1,2 *}$ \\ ${ }^{1}$ MMDN, Université de Montpellier, EPHE, INSERM, Montpellier, France, ${ }^{2}$ Institut Universitaire de France (IUF), Paris, France
}

The glial scar that forms after traumatic spinal cord injury (SCI) is mostly composed of microglia, NG2 glia, and astrocytes and plays dual roles in pathophysiological processes induced by the injury. On one hand, the glial scar acts as a chemical and physical obstacle to spontaneous axonal regeneration, thus preventing functional recovery, and, on the other hand, it partly limits lesion extension. The complex activation pattern of glial cells is associated with cellular and molecular crosstalk and interactions with immune cells. Interestingly, response to $\mathrm{SCl}$ is diverse among species: from amphibians and fishes that display rather limited (if any) glial scarring to mammals that exhibit a wellidentifiable scar. Additionally, kinetics of glial activation varies among species. In rodents, microglia become activated before astrocytes, and both glial cell populations undergo activation processes reflected amongst others by proliferation and migration toward the injury site. In primates, glial cell activation is delayed as compared to rodents. Here, we compare the spatial and temporal diversity of the glial response, following $\mathrm{SCl}$ amongst species. A better understanding of mechanisms underlying glial activation and scar formation is a prerequisite to develop timely glial cell-specific therapeutic strategies that aim to increase functional recovery.

Keywords: spinal cord injury (SCl), glial cells, immune cells, glial scar, glial bridge, rodents, primates, regenerative species

\section{INTRODUCTION}

Traumatic injuries, including spinal cord injury in the adult mammalian central nervous system, induce a glial response that eventually forms a glial scar that is largely occupied by microglia, NG2 glia and astrocytes. The first glial cells to be activated, after injury, are microglia/macrophages that either proliferate and migrate toward the lesion site or, in the case of monocytederived macrophages, infiltrate from the periphery. The activated microglia/macrophages concomitantly express a full repertoire of molecules that modulate glial responses (including microglia/macrophages) but also immune-cell responses (for review, see David and Kroner, 2011; David et al., 2015, 2018). The response of astrocytes eventually leads to the formation of a dense astroglial border surrounding the lesion core, or fibrotic scar (for review, see Yang et al., 2020). In the past decade, the concept that the glial scar has both harmful and beneficial effects has emerged. Indeed, the scar acts as a chemical and physical obstacle to spontaneous axonal regeneration and thus prevents functional recovery. However, the glial scar also limits lesion extension. A better understanding of the complexity of individual cellular (glial and immune cells) and molecular mechanisms induced by SCI as well as their crosstalk remains a major challenge. The cellular dynamics induced by injury are closely reflected by tissue repair and functional 
recovery. Remarkably, amphibians and fishes (for review, see Ghosh and Hui, 2018), but also embryonic/neonatal mammals, exhibit the capacity to both repair injured spinal cord tissues and to achieve functional recovery. Interestingly, these animals display rather limited (if any) glial scarring.

Here, we review the temporal diversity of the glial response, following SCI in rodents, primates, and species that display high regenerative capabilities. Due to the abundant literature on glial scarring, especially in rodents, we selected articles mainly focusing on descriptive characterisations of cellular and/or temporal events induced by SCI in order to highlight the consequences of glial-scar formation kinetics on functional recovery after injury. A better understanding of the mechanisms underlying the time line of glial activation and scar formation is a prerequisite to develop glial-cell-specific therapeutic strategies.

\section{MICE: A MAJOR GLIAL SCAR IS OBSERVED AFTER SPINAL CORD INJURY}

Owing to the extensive availability of genetically modified animals, mice are the most widely used model to study the cellular and molecular responses of glia following SCI (Figures 1, 2 and Table 1).

In mice, immune-cell responses to SCI play a key role in the dynamics of the lesion. The recruitment of neutrophils, following contusion injury, displayed similar kinetics in four mouse strains. An early infiltration, starting as early as $6 \mathrm{~h}$ after injury, led to a peak of neutrophil number between 3 and 14 days post injury (dpi). This was followed by a decrease over the next 4 weeks. Neutrophil numbers, however, remained stable over the next 6 weeks of the study (Kigerl et al., 2006). Compression injury led to similar neutrophil kinetics with two waves of activation that peaked at 3 and $14 \mathrm{dpi}$ (Mawhinney et al., 2012). Consistently, 3$12 \mathrm{~h}$ after contusion injury, expression of chemokines, such as $\mathrm{KC}$ (CXCL1) and MIP-2 (CXCL2) by astrocytes, was followed by the recruitment of neutrophils [and, to a lesser extent, monocytes] through MyD88/IL-1R1 signaling within damaged areas (Pineau et al., 2010). Analysis of the dynamics of cytokine expression after contusion injury has led to the suggestion that the early production (5-15 min) of IL-1 $\beta$ by astrocytes and microglia after injury orchestrates the recruitment of leukocytes (Pineau and Lacroix, 2007). Subsequently, the release of IL-1 $\beta$ and TNF- $\alpha$ (14-28 dpi) induces the recruitment of T lymphocytes (Pineau and Lacroix, 2007). This is in agreement with the biphasic T-cell influx reported after contusion injury, starting at $14 \mathrm{dpi}$, and then decreasing between 2 and 4 weeks and again increasing over the following 2 weeks to reach similar number as at $14 \mathrm{dpi}$ (Kigerl et al., 2006).

Microglia and macrophages are the two predominant immune players in SCI. Resident microglia are within the spinal cord before injury, whereas the monocyte-derived macrophages (MDM) infiltrate the spinal cord from the periphery after the lesion. Crosstalk between both cell types modulates their respective responses to injury and, therefore, contributes to their functions. The dynamic orientation of microglial processes toward the lesion, within the white matter, has been observed by time-lapse two-photon imaging as early as $5 \mathrm{~min}$ after laser injury. This led, soon afterward, to the initiation of myelin debris phagocytosis (Stirling et al., 2014). Similarly, in several mouse strains, contusion and compression injuries induced an early macrophage activation at $6 \mathrm{~h}$ postlesion that further formed phagocytic clusters in the grey matter by $3 \mathrm{dpi}$ (Kigerl et al., 2006; Mawhinney et al., 2012). At 1 day post contusion, microglia rapidly accumulated around the epicenter but decreased in number (cell death, partly by apoptosis) and retracted their processes at the lesion site (Bellver-Landete et al., 2019). From 4 dpi, microglia displayed a round shape and started to express phagocytic markers (Bellver-Landete et al., 2019). From 4 (Bellver-Landete et al., 2019) or 7 (Kigerl et al., 2006; Mawhinney et al., 2012) to $14 \mathrm{dpi}$, activated microglia and MDM peaked and then decreased but remained elevated for up to 6 weeks (Kigerl et al., 2006).

Microglia primarily and transiently proliferated after two severities of spinal cord section, as reflected by an upregulation of genes associated with proliferation at 3 days but not at 7 and 14 days after injury (Noristani et al., 2017). Consistently, after spinal cord contusion, Ki67 expression was observed in 50\% of microglia at the lesion epicenter at $4 \mathrm{dpi}$; the peak of microglia proliferation occurred at $7 \mathrm{dpi}$ and only few (2-6\%) $\mathrm{Ki}^{+} 7^{+}$ microglia persisted at 14 and 35 days (Bellver-Landete et al., 2019). Additionally, microglia proliferated in greater numbers than infiltrating macrophages, and they initiated phagocytosis of damaged axons at 1 dpi (Bellver-Landete et al., 2019). Conversely, infiltrating macrophages started to phagocytose debris at 3-5 dpi and then progressively became the main phagocytic cells in the lesion and persisted chronically (up to $42 \mathrm{dpi}$ ) (Greenhalgh and David, 2014). In addition, the infiltrating macrophages repressed microglia-mediated inflammation and phagocytosis (Greenhalgh et al., 2018). Subsequent to proliferation, microglia were rapidly recruited around the lesion site and accumulated in the core of the lesion 3 days after hemisection (Tang et al., 2015). Similarly, 3 days after spinal cord contusion, $\mathrm{CD}_{11 \mathrm{~b}^{+}}$cells first occupied the periphery of the injury site before being preferentially located in the lesion site 5-56 dpi (Zhu et al., 2015a). Microglia, surrounding infiltrating cells, were located at the interface between infiltrating leukocytes and astrocytes, forming an immune interface through their interaction with both $\mathrm{GFAP}^{+}$astrocytes and blood-derived cells (Bellver-Landete et al., 2019). This "microglial scar" mostly visible from 14 to 35 dpi limited the spread of infiltrating cells outside of the lesion core and expressed IGF-1 that further promoted astrocytic proliferation and astrocytic scar formation (Bellver-Landete et al., 2019).

Analysis of activated microglia/macrophages revealed that, from 3 to 12 months post-injury, few cells were located in the core of the lesion as compared to the glial scar (Camand et al., 2004).

Finally, at a transcriptomic level, microarray experiments on spinal cord segments, centered on the contusion site, have revealed an induction of pro- and anti-inflammatory genes from 1 to $28 \mathrm{dpi}$. However, the upregulation of antiinflammatory genes was more transient (up to 7dpi) than the proinflammatory genes (up to 1 month) (Kigerl et al., 2009). Three days after contusion injury, macrophage-specific transcriptomic analysis revealed an expression profile characteristic of cell 
A
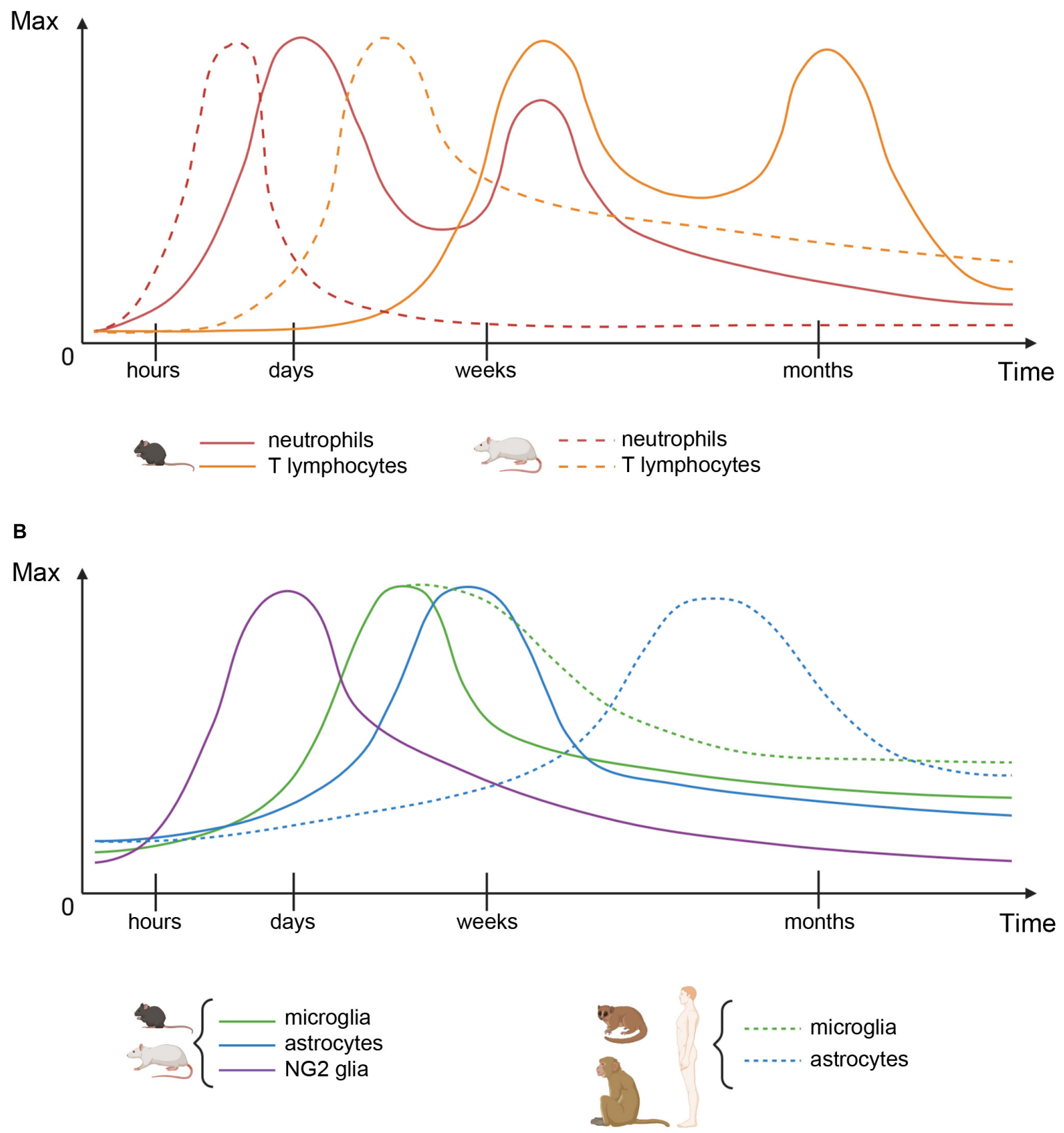

FIGURE 1 | Cellular dynamics after spinal cord injury. (A) Immune cell infiltration patterns in mice (plain lines) and rats (dashed lines). (B) Glial cell numbers in rodents (plain lines) and primates (dashed lines). For each cell type, both graphs represent the number of cells over time, relative to their maximum value.

migration that further evolved at $7 \mathrm{dpi}$ to a typical profile of foam cells (Zhu et al., 2017). Lastly, using RNAseq of microglia/macrophages (CX3CR $1^{+}$cells), following partial and complete spinal cord section, we have shown that microglial activation is dependent on the time post-injury but not on the lesion severity (Noristani et al., 2017). Indeed, the transcriptomic profile at 3 dpi reflected cell proliferation and was associated with neuroprotective genes, whereas, in the 7 and $14 \mathrm{dpi}$, the profile switched to neuroinflammation-associated gene expression. Interestingly, from 3 to $42 \mathrm{dpi}$, over $6 \%$ of microglia expressed astrocytic markers [glial fibrillary acidic protein (GFAP) and vimentin] that may reflect an SCI-induced glial differentiation (Noristani et al., 2017).

Astrocytes play a central role in the formation of the glial scar, following CNS injury. Five days after moderate spinal cord contusion, astrocytes, identified by their expression of GFAP, were seen in the vicinity of the lesion. From $7 \mathrm{dpi}$, astrocytes formed an astroglial scar surrounding the injury site 


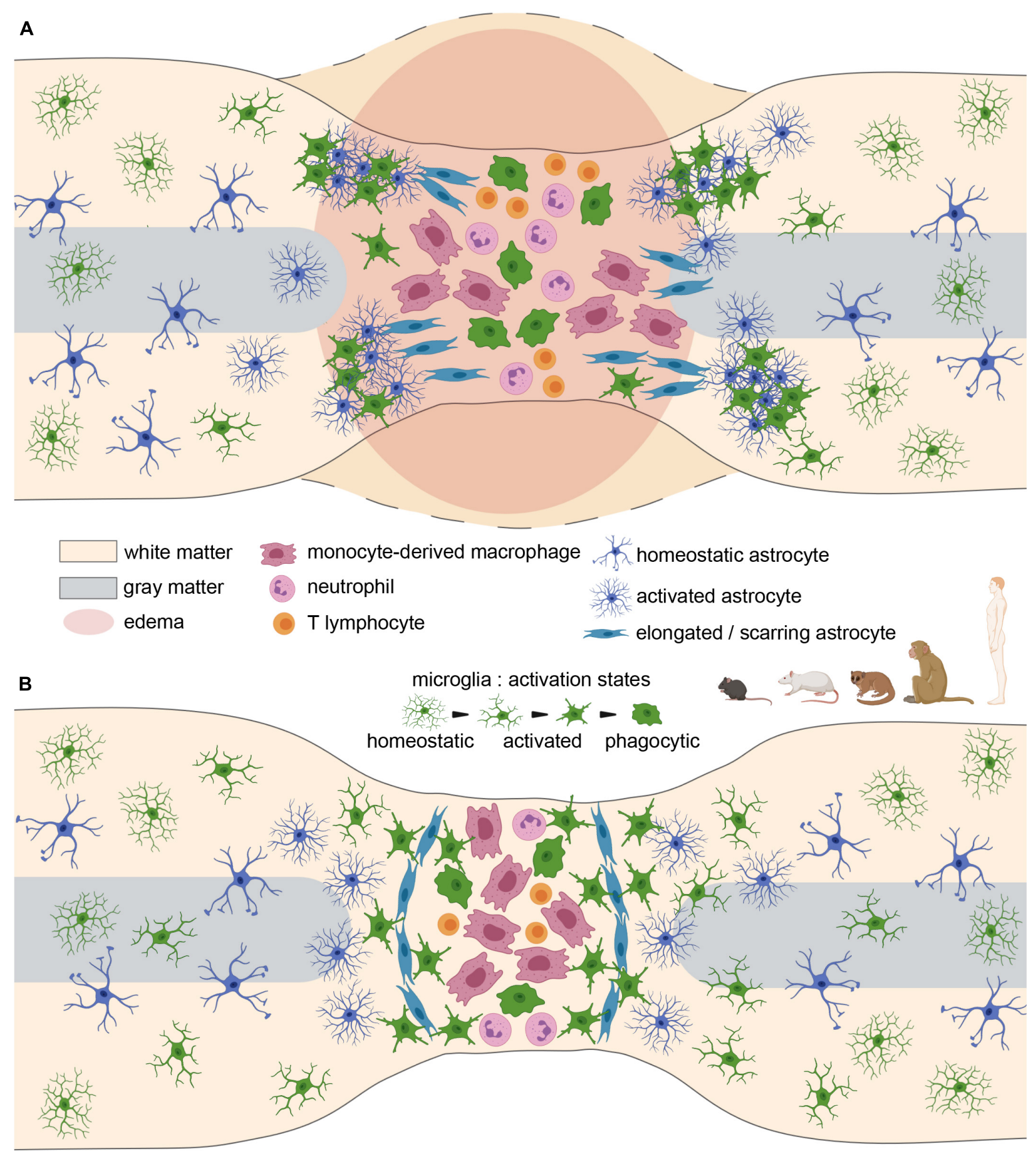

FIGURE 2 | Glial scar formation after spinal cord injury in rodents and primates. (A) Acute stage. Cellular infiltration, reactivity, proliferation, and edema at the lesion site. (B) Glial scar stabilisation at the subacute/chronic stage. Note the substantial role of scarring astrocytes in separating the lesion core from spared tissues.

that stabilised at $14 \mathrm{dpi}$ (Zhu et al., 2015a). In the longer term (56 days after lesion), $\mathrm{GFAP}^{+}$cells were no longer observed in the lesion core (Zhu et al., 2015a). Likewise, 5-14 days following crush injury, astrocyte proliferation, together with the overlapping of astrocytic processes, started to form a dense scar. By 2 weeks postinjury, scar borders surrounded the lesion and restricted fibrotic and inflammatory cells to the core of the injury site, mainly included newly proliferative astrocytes.
This "corral" organisation is STAT3 dependent (Wanner et al., 2013). In mice with spinal crush injury, selective ablation of scar-forming, reactive, and proliferating astrocytes hindered glial scar formation and led to an extensive influx of IBA1positive microglia/macrophages. These findings highlight the constant cross-talk between glial cells and strongly suggest that reactive astrocytes modulate microglia/macrophage number and infiltration (Gu et al., 2019). This is consistent with the increased 
number of proliferating microglia observed at 109 days after hemisection in adult MRL/MpJ mice that possess exceptional regeneration capabilities, which do not form a scar after injury and display a reduced astrocytic response (Thuret et al., 2012).

Eight days after dorsal hemisection of the spinal cord, an overall orientation of astrocytic processes within the rostrocaudal axis was observed immediately adjacent to the lesion. The core of the lesion, with only few astrocytes, remained rather wide from 8 days to 1 month after lesion and diminished by $50 \%$ from 3 to 12 months, following injury (Camand et al., 2004). In the vicinity of the lesion, hypertrophic astrocytes, displaying the classical "stellate shape," were present up to 6 months after injury. Thereafter, GFAP expression returned to a baseline value 6-12 months after injury (Camand et al., 2004). At 3-7 dpi after lateral crush injury, cavity-surrounding, reactive astrocytes have been shown to die by necroptosis. Moreover, induction of necroptotic, astrocytic markers partly resulted from the polarisation of M1 microglia/macrophages (Fan et al., 2016). Strikingly, 8-30 dpi, intense chondroitin sulfate proteoglycans (CSPG) expression was observed in astrocytes. This later almost disappeared. In parallel, PSA-NCAM, which is expressed by astrocytic end feet in the intact spinal cord, was increased in a subpopulation of reactive astrocytes from 8 to $30 \mathrm{dpi}$. This expression remained elevated at later time points (Camand et al., 2004). After severe crush injury, Cspg5 (neuroglycan C) and Cspg4 (NG2) were upregulated in scar-forming astrocytes. Furthermore, both NG2 and CSPG5 proteins were observed in the glial scar (Anderson et al., 2016), suggesting that astrocytes also participated in extracellular matrix dynamics.

The origin of scar-forming astrocytes remains to be elucidated. Newly formed astrocytes accumulated at the edge of the lesion by 7 days after moderate contusion injury and then remained at a constant level up to 49 days. Similarly, amongst the proliferative cells, an increased proportion of astrocytes was observed in the spared white matter (White et al., 2010). In parallel, radial glial cells $\left(\mathrm{BLBP}^{+}\right)$presented an early and sustained increase in incidence at the edge of the lesion and in the preserved white matter conversely to their transient presence in the spared grey matter and central canal (White et al., 2010). There is an ongoing debate as to the origin of the newly proliferative scar-forming astrocytes. Indeed, scar-forming astrocytes were either reported to mainly (Sabelstrom et al., 2013) or minimally (Ren et al., 2017) originate from ependyma-derived progeny. This discrepancy on the ependymal contribution to newly scar-forming astrocyte may depend on whether or not the ependyma was directly damaged by the primary injury (Ren et al., 2017). Finally, we investigated astrocytic plasticity overtime using RNAseq analysis of a pure population of astrocytes, following hemior complete spinal cord section and demonstrated a time and severity-dependent deregulation of gene expression. However, in both injury severities, over $10 \%$ of mature (as opposed to newly formed) astrocytes underwent an injury-induced transdifferentiation toward neuronal progenitors (Noristani et al., 2016; Noristani and Perrin, 2016).

Finally, two NG2-expressing cell populations (glial cells and pericytes) also participate in scar formation. From 1 to 11 days after contusion injury, dividing oligodendrocyte progenitors, the
$\mathrm{NG}^{+}$glial cells, strongly outnumber dividing $\mathrm{NG}^{+}$pericytes and were restricted at the lesion border and in the spared tissue (Hesp et al., 2018). From 8 days to 6 months, an increased expression of NG2 was also reported in the glial scar, following hemisection; it returned to control value 1 year after injury (Camand et al., 2004). Interestingly, ablation of $\mathrm{NG}_{2}{ }^{+}$cells induced a less-dense astrocytic border associated with macrophages infiltration (Hesp et al., 2018).

Overall, in mice, recruitment and infiltration of immune cells precede microglial and astrocytic responses (Figure 1). However, a complex molecular crosstalk between all cell populations orchestrates the formation of a well-defined and dense glial scar (Figure 2 and Table 1).

\section{RATS: A MAJOR GLIAL SCAR IS ALSO OBSERVED AFTER SPINAL CORD INJURY BUT IMMUNE INFILTRATION APPEARS EARLIER THAN IN MICE}

Rats display an overall pathophysiological response to SCI that mimics some features of the human response, such as the formation of cavities. This is not observed in mice. Rats are thus the most widely used model in SCI even if they are not predominant amongst rodents in studies focusing on glia (Figure 2 and Table 2).

In rats, following spinal cord injury, the cellular response in the lesion is initiated by immune cells. The majority of studies have been carried out using immunohistochemistry, and only a few have resorted to flow cytometry. As early as 1$3 \mathrm{~h}$, following partial spinal cord section, a few neutrophils adhere to the inner surface of blood vessels. Then, from 6 to $24 \mathrm{~h}$, a large number of neutrophils are found at the site of the primary lesion. Thereafter, they disappear (Dusart and Schwab, 1994). Similarly, 1 day following contusion injury, the initial phase of inflammation consisted of an early neutrophil number peak that declines afterward. However, neutrophils persist for many months, and a positive correlation between contusion severity and the number of neutrophils has been reported (Beck et al., 2010). Finally, neutrophil and lymphocyte peaks were observed 3 days after dorsal hemisection of the spinal cord; neutrophils completely disappeared 7 days after lesion, whereas $\mathrm{T}$ cells displayed a strong decrease but remained present (Pruss et al., 2011). In agreement with this, following contusion injury, early $\mathrm{T}$ cell infiltration peaked between 3 and 7 dpi (Popovich et al., 1997; Sroga et al., 2003) and declined by $50 \%$ over the next 3 weeks (Sroga et al., 2003). Lymphocyte infiltration was paralleled by microglial activation (Popovich et al., 1997) and dendritic-cell influx (Sroga et al., 2003). Using flow cytometry, after contusion injury, Beck et al. show similar $\mathrm{T}$ cells dynamics, but with a slightly delayed infiltration (from 7 to 9 dpi peaking at Day 9), followed by a decrease at 10 dpi and persistence throughout the 6 months study follow-up (Beck et al., 2010).

Glial cell dynamics, including microglia/macrophages, oligodendrocytes, astrocytes, and NG2-expressing cells, have 
TABLE 1 | Studies demonstrating roles of the glial and immune cells after SCl in mice.

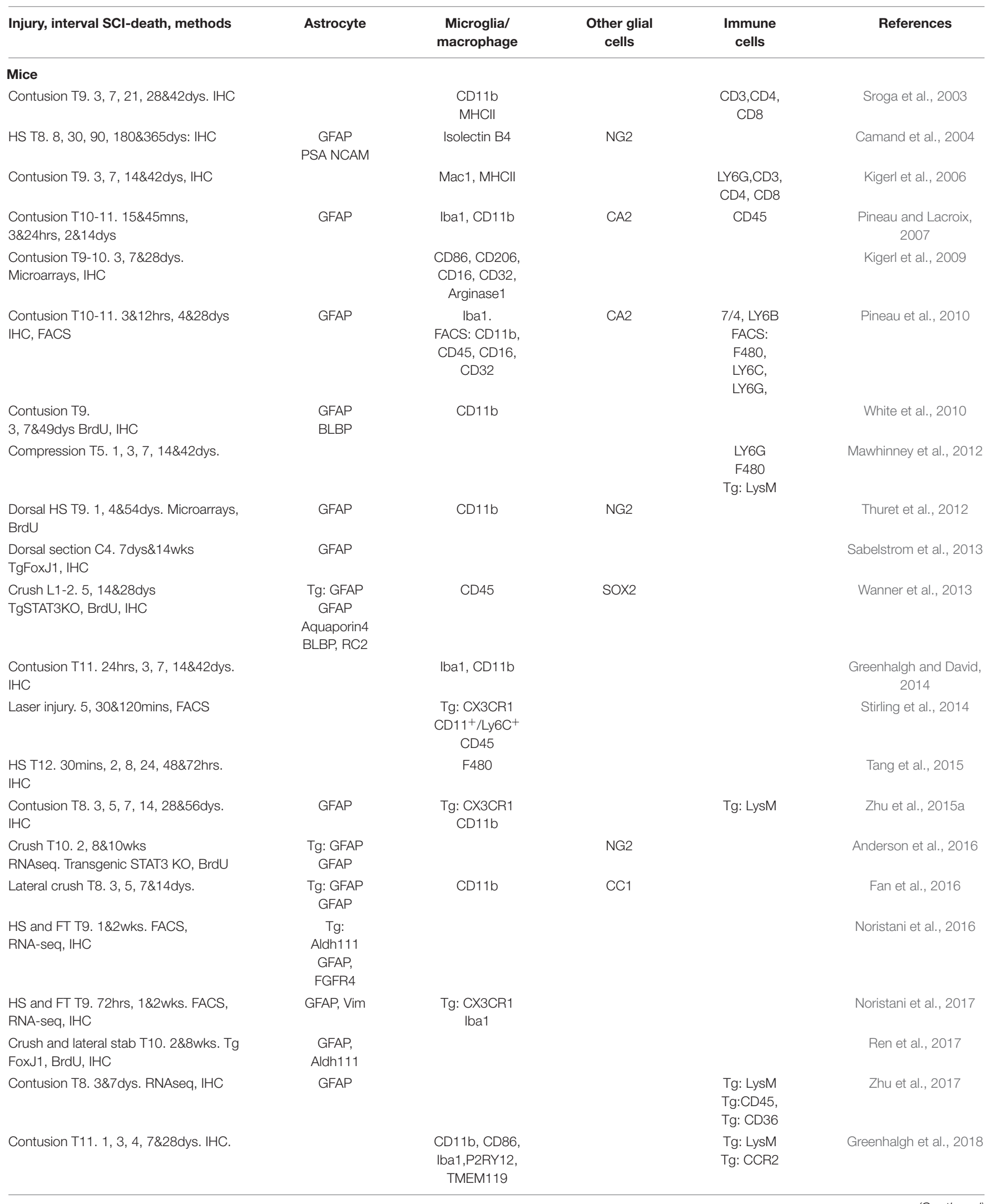


TABLE 1 | (Continued)

\begin{tabular}{|c|c|c|c|c|c|}
\hline Injury, interval SCl-death, methods & Astrocyte & $\begin{array}{l}\text { Microglia/ } \\
\text { macrophage }\end{array}$ & $\begin{array}{l}\text { Other glial } \\
\text { cells }\end{array}$ & $\begin{array}{l}\text { Immune } \\
\text { cells }\end{array}$ & References \\
\hline $\begin{array}{l}\text { Lateral contusion C5. 1, 3, 7, 11, } \\
14 \& 21 \text { dys, IHC }\end{array}$ & GFAP & & $\begin{array}{l}\text { Tg: NG2 } \\
\text { ablation } \\
\text { Olig2 }\end{array}$ & & Hesp et al., 2018 \\
\hline $\begin{array}{l}\text { Contusion T9-10 } \\
1,4,7,14 \& 35 \text { dys, IHC }\end{array}$ & $\begin{array}{l}\text { GFAP } \\
\text { SOX9 }\end{array}$ & $\begin{array}{c}\text { R26-TdT } \\
\text { Tg: LysM } \\
\text { Tg: CX3CR1 } 1 \text { re } \\
\text { CD68,P2RY12, }\end{array}$ & & & $\begin{array}{l}\text { Bellver-Landete et al., } \\
2019\end{array}$ \\
\hline $\begin{array}{l}\text { Crush T8. 2, 4\&6wks } \\
\text { Lentiviral-induced ablation, BrdU, } \mathrm{IHC}\end{array}$ & $\begin{array}{l}\text { Lv-GFAP to } \\
\text { ablate } \\
\text { astrocytes }\end{array}$ & lba1 & & & Gu et al., 2019 \\
\hline $\begin{array}{l}\text { Crush T10 } \\
3 \& 7 \text { dys, } 10 w k s, I H C \text {, RNA-seq. }\end{array}$ & GFAP & $\begin{array}{c}\text { CD68, P2Y12 } \\
\text { RNA: } \\
\text { CD11bTg: } \\
\text { CX3CR1 }{ }^{\text {cre }} \\
\text { Tg: CSF1R }{ }^{\text {fl/fl }}\end{array}$ & & & Li et al., 2020 \\
\hline
\end{tabular}

FACS, flow cytometry; hrs, hours; min, minutes; dys, days; wks, weeks; mths, months; yrs, years; IHC, immunohistochemistry; C, cervical; T; thoracic; L, lumbar; HS, hemisection; FT, full transection; Tg, transgenic.

been widely analysed in rat models of SCI. The partial section of the spinal cord first induced microglia/macrophage proliferation at the lesion site that predominated at $48 \mathrm{~h}$, leading to a highest density between 4 and 8 dpi. Then, 2 weeks after injury, microglia progressively disappeared from the lesion site concomitantly with the formation of a cavity that was further surrounded by a scar composed of microglia and astrocytes (Dusart and Schwab, 1994). Similarly, microglial activation peaked within the contusion epicenter between 3 and 7 days (Popovich et al., 1997; Sroga et al., 2003) and plateaued between 7 and 28 dpi distal to the lesion (Popovich et al., 1997). Alongside, monocyte influx and macrophage activation started at 7 dpi (Popovich et al., 1997).

The number of contusion-induced microglia/macrophages increased with the injury severity and displayed a biphasic response, with a first peak at $7 \mathrm{dpi}$, followed by a very low cell number at $14 \mathrm{dpi}$, increasing to a second peak at 60 days; microglia/macrophage number then remained elevated throughout 180 dpi (Beck et al., 2010). In agreement with this, a peak of microglia/macrophages displaying thick and branched processes was observed 1 week after dorsal hemisection, followed by a slow decline in number; however, microglia/macrophages also remained elevated 70 days after the lesion (Pruss et al., 2011). Following contusion injury, microglia/macrophages located in the spared white matter proliferated from 1 to 7 days, reaching a maximum on Day 3. By 6 weeks postlesion, few remaining proliferative microglia/macrophages were present (Zai and Wrathall, 2005). Finally, after dorsal funiculotomy, in ascending and descending pathways undergoing Wallerian degeneration at both subacute (10 dpi) and chronic ( $30 \mathrm{dpi})$ stages, the numbers of microglia $(\mathrm{OX} 42+)$ and macrophages $\left(\mathrm{ED}^{+}\right)$were higher than in sham animals. However, a decrease in cell number between subacute and chronic stages was seen only in the ascending tract (Wang et al., 2009). In the same animals, the number of astrocytes was also increased, $c f$. sham animals, at both stages but, conversely to microglia, remained stable between stages (Wang et al., 2009).
One week after dorsal hemisection, few astrocytes were located in the lesion site; however, several also began to surround the injury site. At 2 weeks, astrocytes and microglia then formed a scar (Dusart and Schwab, 1994). This is consistent with contusion injury (Popovich et al., 1997; Zhu et al., 2015b) where an astroglial scar surrounded the lesion, whereas cavitation sites were occupied by microglia and macrophages (Popovich et al., 1997). Interestingly, 1 and/or 4 months after injury, astrocytes expressed several proteins, such as gamma1- and alpha1-laminin, type IV collagen, and FGF2, which participated in the chronic persistence of the glial scar (Liesi and Kauppila, 2002). Likewise, 2 months after the complete section of the thoracic spinal cord, astrocytes produced CSPG in the scar (Li et al., 2018), thus suggesting that, as seen in mice, astrocytes contribute to extracellular matrix dynamics.

From 1 to 7 days following contusion injury, astrocytes, oligodendrocytes, and NG2 glial precursors proliferated in the spared white matter, with a peak on Day 3. About $50 \%$ of the astrocytes and oligodendrocytes located in the residual white matter, next to the injury site, however, were lost by $24 \mathrm{~h}$ (Zai and Wrathall, 2005). During the chronic phase (6 weeks after lesion), the remaining proliferative cells consist of mature astrocytes or oligodendrocytes (50\%) and few expressing NG2 (Zai and Wrathall, 2005). After moderate contusion, the expression level of NG2 increased between 3 and 7 days post injury and remained chronically elevated. In contrast to the spared surrounding tissue, within the lesion site, few, if any, NG2 ${ }^{+}$cells were oligodendrocytes (McTigue et al., 2006). Within areas undergoing Wallerian degeneration, following dorsal funiculotomy, oligodendrocyte density (Olig2) decreased at subacute (10 days) and chronic (30 days) stages, although Olig2 ${ }^{+}$cells were still present (Wang et al., 2009).

Taken together, these results demonstrate that the glial response to SCI exhibits similar dynamics in rats and mice; however, the immune cell response occurs earlier in rats than in mice (Figures 1A,B). 
TABLE 2 | Studies demonstrating roles of the glial and immune cells after SCl in rats.

\begin{tabular}{|c|c|c|c|c|c|}
\hline Injury, interval SCI-death, methods & Astrocyte & $\begin{array}{c}\text { Microglia/ } \\
\text { macrophage }\end{array}$ & $\begin{array}{l}\text { Other glial } \\
\text { cells }\end{array}$ & Immune cells & References \\
\hline \multicolumn{6}{|l|}{ Rats } \\
\hline $\begin{array}{l}\text { Partial section, } 1,3,6,12,24 \mathrm{hrs} \text { and } 2 \text {, } \\
4,8,14 \& 12 \mathrm{wks} \text {. } \\
\mathrm{IHC}, \mathrm{HC}\end{array}$ & GFAP & CD11b, ED1 & & Cresyl violet & Dusart and Schwab, 1994 \\
\hline $\begin{array}{l}\text { Contusion T8, 12, 72hrs, 7, 28dys } \\
\text { IHC }\end{array}$ & GFAP & $\begin{array}{l}\text { CD11b, ED1, } \\
\text { MHCII }\end{array}$ & & CD5 & Popovich et al., 1997 \\
\hline $\begin{array}{l}\text { Stab dorsal } \\
1 \& 4 \mathrm{mths}\end{array}$ & GFAP & & & & Liesi and Kauppila, 2002 \\
\hline $\begin{array}{l}\text { Contusion T9, } \\
3,7,21,28 \& 42 \text { dys } \\
\text { IHC }\end{array}$ & & CD11b, MHCll & & $\begin{array}{l}\text { CD4, CD8, } \\
\text { CD11C }\end{array}$ & Sroga et al., 2003 \\
\hline $\begin{array}{l}\text { Contusion T8 } \\
1,3 \& 7 \text { dys, 6wks } \\
\text { BrdU, IHC }\end{array}$ & GFAP & CD11b & $\begin{array}{l}\text { NG2 } \\
\text { CC1 }\end{array}$ & & Zai and Wrathall, 2005 \\
\hline $\begin{array}{l}\text { Moderate contusion } \\
\text { T8 } \\
3,7,28 \text { \&70dys }\end{array}$ & & & $\begin{array}{l}\text { NG2 } \\
\text { P75 } \\
\text { P0 }\end{array}$ & & McTigue et al., 2006 \\
\hline $\begin{array}{l}\text { Dorsal funiculotomy } \\
\text { T8. 1hr, 10\&30dys } \\
\text { IHC }\end{array}$ & GFAP & $\begin{array}{l}\text { CD11b } \\
\text { ED1 } \\
\text { CD68 }\end{array}$ & Olig2 & & Wang et al., 2009 \\
\hline $\begin{array}{l}\text { Contusion T8 (3 severities) } \\
\text { FACS: 0-10dys, 14, 90\&180dys, } \\
\text { IHC; } 1,7,14 \& 90 \text { dys }\end{array}$ & & $\begin{array}{l}\text { FACS:ED1, } \\
\text { CD11b } \\
\text { IHC: ED1 }\end{array}$ & & $\begin{array}{l}\text { FACS\&IHCCD3, } \\
\text { PME }\end{array}$ & Beck et al., 2010 \\
\hline $\begin{array}{l}\text { Dorsal HS } \\
3,7,14 \& 28 d y s, \mathrm{HC}\end{array}$ & & $\begin{array}{c}\text { ED1, CD8, } \\
\text { CD86, CD206 }\end{array}$ & & MPO, CD43 & Pruss et al., 2011 \\
\hline $\begin{array}{l}\text { ContusionT8 } \\
\text { 56dys, IHC }\end{array}$ & GFAP & & & & Zhu et al., 2015b \\
\hline $\begin{array}{l}\text { FT T8 } \\
2,8 w k s I H C\end{array}$ & Morphology & & & & Li et al., 2018 \\
\hline $\begin{array}{l}\text { FT T9 } \\
48 h r s ~ I H C\end{array}$ & & & $\begin{array}{c}\text { Nr3c1, } \\
\text { ependymal } \\
\text { glia is a } \\
\text { Glcc target }\end{array}$ & & Nelson et al., 2019 \\
\hline
\end{tabular}

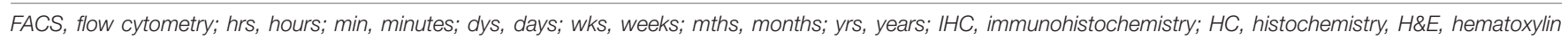
eosin; C, cervical; T, thoracic; L, lumbar; HS, hemisection; FT, full transection.

\section{NONHUMAN PRIMATES: A MAJOR ASTROCYTIC SCAR IS NOT OBSERVED AFTER SPINAL CORD INJURY}

The neuroanatomical organisation of the central nervous system and responses to injury differ between rodents and primates (Courtine et al., 2007); thus, several SCI models in various strains of nonhuman primate have been developed. However, investigation of the glial response following injury is sparse, particularly early after injury (Figure $\mathbf{2}$ and Table $\mathbf{3}$ ).

One hour after spinal cord compression in Macaca cynomolgus, an increased IBA1 immunoreactivity was observed adjacent to the injury site; no modification in astrocytes was seen (Miller et al., 2012). Spatiotemporal investigation of cellular responses following lateral spinal cord hemisection in Macaca fascicularis highlighted that, 1 and 4 weeks post-injury, microglia displayed morphological changes and became amoeboid in the epicenter and the spared contralateral white matter ( $\mathrm{Wu}$ et al., 2013). The number of IBA1 positive cells remained stable at 1 week and decreased 4 weeks after lesion in both locations. However, activated microglia/macrophages $\left(\mathrm{CD}^{+} 8^{+}\right)$ increased in number at the two time points in the same locations. Concomitantly, at the lesion epicenter, a decreased astrocyte number was reported and astrocytes became hypertrophic contralateral to the lesion. Importantly, a major astrocytic glial scar surrounding the lesion site was never observed (Wu et al., 2013). In the same species and lesion model, 1 and 4 weeks after SCI, an increased number of microglia $\left(\mathrm{OX} 42^{+}\right)$was detected within areas undergoing Wallerian degeneration (Shi et al., 2009). Morphologically, microglia were branched but displayed a large cell body and short processes. None, although, were amoeboid (Shi et al., 2009). No modifications in astrocytic morphology or number were observed.

Longitudinal gene expression analysis following contusion of the cervical spinal cord in Callithrix jacchus (marmoset) revealed that the inflammatory response peaked at 1 week post SCI and 
TABLE 3 | Studies demonstrating roles of the glial and immune cells after SCl in primates.

\begin{tabular}{|c|c|c|c|c|c|}
\hline Species, strain, sex, age & $\begin{array}{l}\text { Interval SCldeath, } \\
\text { methods }\end{array}$ & Injury type, level & Astrocyte & $\begin{array}{l}\text { Microglia/ } \\
\text { macrophage }\end{array}$ & References \\
\hline \multicolumn{6}{|l|}{ Nonhuman primates } \\
\hline $\begin{array}{l}\text { Callitrhrix jacchus (Marmoset), } \\
\text { 20F, adults }\end{array}$ & $10 w k s, I H C$ & 3 contusion severities, C5 & GFAP & & Iwanami et al., 2005 \\
\hline Macaca fascicularis9 M, 5-6yrs & $1 \& 4 w k s, \Vdash H C$ & Lateral HS, T8-9 & GFAP & OX42 & Shi et al., 2009 \\
\hline Macacacynomolgus1M & $1 \mathrm{hr}, \mathrm{IHC}$ & Balloon compression & GFAP & lba1 & Miller et al., 2012 \\
\hline Macaca fascicularis4M, 4-6 yrs & 7\&30dys, $I \mathrm{HC}$ & Lateral HS, T8-9 & GFAP & $\begin{array}{l}\text { lba1 } \\
\text { CD68 }\end{array}$ & Wu et al., 2013 \\
\hline $\begin{array}{l}\text { Callitrhrix jacchus (Marmoset), } \\
\text { 16F, 2yrs }\end{array}$ & $\begin{array}{c}\text { 1, 2, 4\&6wks, } \\
\text { microarrays\& } \\
\text { RNA-seq. } \\
\text { 1, 2\&6wks, IHC }\end{array}$ & Contusion, C5 & GFAP & Iba1 & Nishimura et al., 2014 \\
\hline $\begin{array}{l}\text { Macaca mulatta } \\
6 \mathrm{M}, 3.5-4.2 \mathrm{yrs}\end{array}$ & 6mths, $\Vdash \mathrm{HC}$ & 2 contusion severities, T9 & GFAP & & Ma et al., 2016 \\
\hline $\begin{array}{l}\text { Chlorocebussabaeus (african } \\
\text { green monkey) } \\
\text { 12M, 5-10yrs }\end{array}$ & 12wks, IHC & lateral HS, T9-10 & GFAP & lba1 & Slotkin et al., 2017 \\
\hline $\begin{array}{l}\text { Microcebus murinus } \\
8 \mathrm{M}, 2 \text { yrs }\end{array}$ & 3mths, IHC & Lateral HS, T12-L1 & GFAP & lba1 & Le Corre et al., 2018 \\
\hline $\begin{array}{l}\text { Microcebus murinus } \\
10 \mathrm{M}, 2 \mathrm{yrs}\end{array}$ & 3mths, $\mathrm{IHC}$ & Lateral HS, T12-L1 & GFAP & lba1 & Poulen et al., 2021 \\
\hline \multicolumn{6}{|l|}{ Human } \\
\hline 27 cases, 5F\&22M, 8-86 yrs & 8 dys-23yrs, $I H C$ & $\begin{array}{l}\text { Para- or tetraplegia } \\
\text { C, T\&L }\end{array}$ & GFAP & & Puckett et al., 1997 \\
\hline $\begin{array}{l}13 \text { cases } \\
21-85 y r s\end{array}$ & 2 dys- 30 yrs, IHC & $\begin{array}{l}\text { Complete para- or } \\
\text { tetraplegia } \\
\text { C, T\& } \mathrm{L}\end{array}$ & GFAP & & Buss et al., 2004 \\
\hline $\begin{array}{l}180 \text { cases } \\
\text { Ratio } 5: 1 \mathrm{M}: \mathrm{F} \\
8 \mathrm{mths} \text { to } 92 \mathrm{yrs}\end{array}$ & $\begin{array}{l}\text { Instantaneous- } \\
\text { 51yrs, IHC\&HC }\end{array}$ & Predominantly C & GFAP & $H \& E$ & Norenberg et al., 2004 \\
\hline $\begin{array}{l}11 \text { cases, } 2 F \& 9 M \\
18-83 y r\end{array}$ & 30min - 19dys, IHC & Para or tetraplegia. & GFAP & $\mathrm{MHCll}$ & Yang et al., 2004 \\
\hline 1 case, 56yrs & 2yrs IHC & Complete C6 injury & GFAP & & Guest et al., 2005 \\
\hline 28 cases, 8F\&20M, 6-88yrs & $\begin{array}{c}\text { Instantaneous - 1yr, } \\
\text { IHC }\end{array}$ & $\begin{array}{c}\text { Contusion, } \\
\text { compression\&lacerationC1- } \\
\text { T12. }\end{array}$ & & CD68 & Fleming et al., 2006 \\
\hline $\begin{array}{l}3 \text { cases, } 1 F \& 2 M, 49,59 \text { and } \\
80 y r s\end{array}$ & $15,20,60$ dys, $I H C$ & Contusion, C & & CD68 & Chang, 2007 \\
\hline 1 case & 5dys, $\mathrm{IHC}$ & & GFAP & & Fan et al., 2016 \\
\hline $\begin{array}{l}22 \text { cases, } 6 F \& 16 M \\
15-80 y r s\end{array}$ & $<1-413$ dys, $I \mathrm{HC}$ & $\mathrm{T} \& \mathrm{C}$ & $\mid \mathrm{BA} 1$ & $\begin{array}{l}\text { TMEM119 } \\
\text { P2RY12 }\end{array}$ & Zrzavy et al., 2021 \\
\hline
\end{tabular}

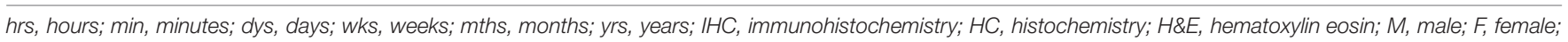
C, cervical; T, thoracic; L, lumbar; HS, hemisection.

remained elevated up to 6 weeks following injury (Nishimura et al., 2014). The inflammatory response thus required a longer time to occur than in rodents. Concomitantly, IBA1 positive cells and proliferative microglia were present at the lesion epicenter at 1 week, decreased at 2 weeks, and were absent 6 weeks after injury. The rim of the lesion was delineated by astrocytes only at 6 weeks. In the same species and lesion model but with graded severities, 10 weeks after trauma, GFAP was expressed in a severity-dependent manner at the border of the lesion (Iwanami et al., 2005).

Three months following hemisection of the thoracic spinal cord in Chlorocebus sabaeus (African green monkey), astrocytes and microglia/macrophages were present at the rim of the lesion
(Slotkin et al., 2017). In Microcebus murinus, a small lemur, we have shown that, at 3 months following lateral hemisection of the thoracic spinal cord, the glial reactivity was increased adjacent to the lesion. Additionally, an increase in microglia/macrophage and astrocyte reactivity was present within the grey matter, only rostral to the lesion. Moreover, rostral to the lesion a marked increase in microglia/macrophage reactivity was also observed on the lesion side of the dorsal funiculus (Le Corre et al., 2018; Poulen and Perrin, 2018; Poulen et al., 2021).

Finally, in Macaca mulatta, 6 months following contusive injury of the thoracic spinal cord, the density of astrocytes was decreased in the lesion penumbra but increased in the spared white matter (Ma et al., 2016). 
Overall, the microglial response appears similar as in rodents conversely to the astrocytic response that occurs slower and does not lead to the formation of a major astrocytic scar. In some species, the inflammatory response is also slower than in rats and mice (Figure 1B).

\section{HUMAN: A MAJOR ASTROCYTIC SCAR IS NOT OBSERVED AFTER SPINAL CORD INJURY AND ASTROCYTIC RESPONSE IS SLOWER THAN IN OTHER SPECIES}

Similarly, to animal models of spinal cord injury, microglial/macrophage cells display the earliest cellular response to injury (Figure 2 and Table 3). From 0 to $4 \mathrm{~h}$ after injury, a modest number of phagocytic microglia/infiltrating monocytederived macrophages were observed at the injury site (Fleming et al., 2006). Activated microglia have also been detected as early as $30 \mathrm{~min}$ (Yang et al., 2004) and 1 day (Norenberg et al., 2004; Fleming et al., 2006) after spinal cord injury. Consequently, activated microglia were observed in the surviving area 5 days after SCI (Yang et al., 2004), and numerous amoeboid microglia were present adjacent to areas of necrosis from 5 to 10 days post injury. These persisted for weeks (and up to 1 year) in the proximity of the injury site (Norenberg et al., 2004; Fleming et al., 2006; Chang, 2007). A recent analysis of 22 human SCI cases has highlighted a time-dependent activation of microglia and macrophages associated with a spatial-dependent inflammatory pattern composed of a predominantly pro-inflammatory lesion rim and a lesion core displaying a dual pro- and antiinflammatory phenotype (Zrzavy et al., 2021). The initial loss of microglia within the core of the lesion at the acute stage (1-3 days post-SCI) was followed in the early subacute stage (4-21 days post-SCI) by a massive increase of IBA1-expressing cells in the core and the rim of the lesion. Within the lesion rim, the majority of these cells were microglia (80\% TMEM119 ${ }^{+}$) conversely to the core where their proportion dropped to $10 \%$ and was associated with an amoeboid shape and a large number of $\mathrm{CD} 8^{+}$macrophages. Importantly, IBA1 ${ }^{+} / \mathrm{TMEM} 19^{+}$cells within the lesion rim mostly resulted from local microglial proliferation (Zrzavy et al., 2021). Later (21-90 days post-injury), the number of macrophages in the lesion core decreased but remained elevated and displayed a dispersed pattern in the lesion rim. At chronic stages (90 days to 1.5 years post-lesion), cystic cavitations appeared and were surrounded by a rim of activated astrocytes and macrophages. Overall, microglia are, thus, the predominant cells in the proximity of the injury during lesion maturation, and recruited monocytes/macrophages are dominant within the lesion core.

Only a few studies have investigated the temporal astrocytic response following spinal cord injury in man. The presence of activated astrocytes has been described to appear either early after the injury (from 4 days) (Buss et al., 2004; Norenberg et al., 2004) at 21-90 days post-injury in the lesion rim (Zrzavy et al., 2021) or as long as 4 months after lesion (Puckett et al., 1997). In one spinal cord sample, 5 days after SCI, necroptotic markers were found in $\mathrm{GFAP}^{+}$cells located in the lesion site, suggesting that reactive astrocytes may undergo necroptosis (Fan et al., 2016). Clusters of activated astrocytes were also observed one or two segments away from the lesion site in both white and grey matters from 4 to 12 days after SCI. Thereafter, activated astrocytes were evenly distributed over the whole section close to the lesion site from 24 days to 4 months after injury (Buss et al., 2004). Several days after injury, hypertrophic astrocytes appeared at the edge of the lesion and peaked at 2-3 weeks (Norenberg et al., 2004). Moreover, activated astrocytes surrounded cystic cavities from 90 days to 1.5 years post injury (Zrzavy et al., 2021). In another study, astrocytes displayed a slight increase in GFAP reactivity, in processes in contact with the phagocytes, 4 to 12 months after injury, followed by a hypointense GFAP signal, persisting up to 23 years after injury (Puckett et al., 1997). At longer post-injury time (1-30 years), dense GFAP-positive staining was present in the white matter that had undergone Wallerian degeneration (Buss et al., 2004). Two years following complete spinal cord injury, a dense GFAP reaction was observed in the peri-injury region (Guest et al., 2005). These differences may result from the heterogeneity of the lesions observed in man.

Overall, the astrocytic response in man seems to occur slower than in animal models, including nonhuman primates, and the astroglial processes that create an impenetrable barrier were almost never seen (Norenberg et al., 2004) (Figures 1B, 2).

\section{SPECIES WITH HIGH REGENERATIVE CAPACITIES: A GLIAL BRIDGE MORE THAN A GLIAL SCAR}

Interestingly, vertebrates, such as fishes, urodele amphibians, and some reptiles, that possess a remarkable capacity to regenerate injured spinal cord tissue and to recover associated functions also display rather limited (if any) glial scarring (Figure 3 and Table 4). Radial glial cells are the main (and often the only) representant of astrocytes in lower vertebrates (for review, see Verkhratsky et al., 2019). Here, we kept the names "radial glia," "GFAP-expressing cells" or even "astrocytes" as they appeared in the original publications.

No reactive, fibrous astrocytes have been described at the injury site, after spinal cord lesion, in either juvenile or adult Amybstoma mexicanum (axolotl). Astrocytes, initially present in the white matter, first disappeared from the lesion site and reappeared 1 month after injury concomitantly with regenerating axons (O'Hara et al., 1992). In the same study, in vitro experiments suggested that the formation of a scaffold resulting from mesenchymal epithelial transition permits axon regeneration (O'Hara et al., 1992). Similarly, in the adult salamander, following the complete spinal cord section, axons regrew and crossed the lesion site (Zukor et al., 2011). No scar formation was observed; however, astrocytes were present but not hypertrophic. Astrocytic cells did not migrate into the injury site, but $\mathrm{GFAP}^{+}$processes crossed the lesion site, and axons appeared to regrow on this glial support. Additionally, a non-detrimental inflammatory response was 
A

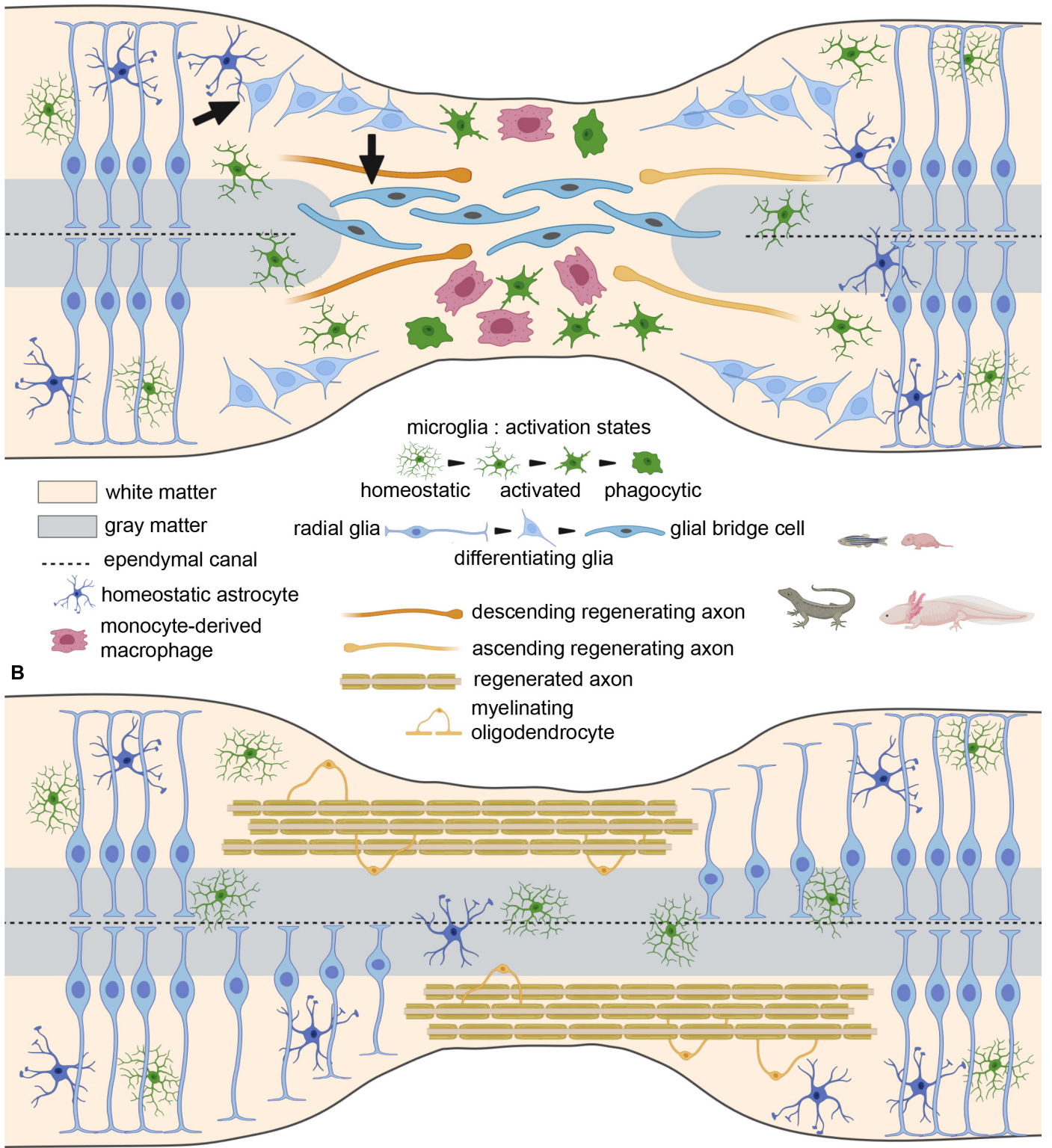

FIGURE 3 | The glial bridge after spinal cord injury in species with high regenerative capacities and perinatal mammals. (A) Tissue clearance, glial bridge, and axon sprouting at the acute/subacute stage. Arrows represent the involvement of radial glia in the glial bridge formation. (B) Remyelination and return to homeostasis at the chronic stage.

reported (Zukor et al., 2011). Likewise, following SCI in adult zebrafishes (Goldshmit et al., 2012) and larvae (Briona and Dorsky, 2014), GFAP-expressing cells became elongated and formed a "glial bridge" that joins the sides of the damaged spinal cord in the absence of glial scar formation. No reactive astrocytes were observed. In adults, within 3-5 days post injury, $\mathrm{GFAP}^{+}$glial cells proliferated in and around the central canal. Concomitantly, a few proliferative macrophages were also reported outside of the central canal (Goldshmit et al., 2012). Five days after injury, proliferative cells at the edge of the lesion expressed a low level of GFAP, and, from 7 to 10 days after SCI, GFAP ${ }^{+}$cells migrated into the site of the lesion and acquired a bipolar morphology. Then, from 2 to 3 weeks post SCI, a "glial bridge" formed of GFAP-expressing bipolar cells appeared in the lesion site. From 4 weeks post lesion, this permissive bridge supported axogenesis. Interestingly, by 3 (and up to 5) days post injury, oligodendrocyte precursors and motor neuron progenitors (olig2 ${ }^{+}$) bridged the injury site in zebrafish larvae (Anguita-Salinas et al., 2019). The mechanisms of bridge formation appeared to be Fgf- (Goldshmit et al., 2012) but also ctfg (connective tissue growth factor) dependent (reviewed in Cigliola et al., 2020). In zebrafish, bridge formation depends on 
TABLE 4 | Studies demonstrating roles of the glial and immune cells after SCl in species with high regenerative capacities.

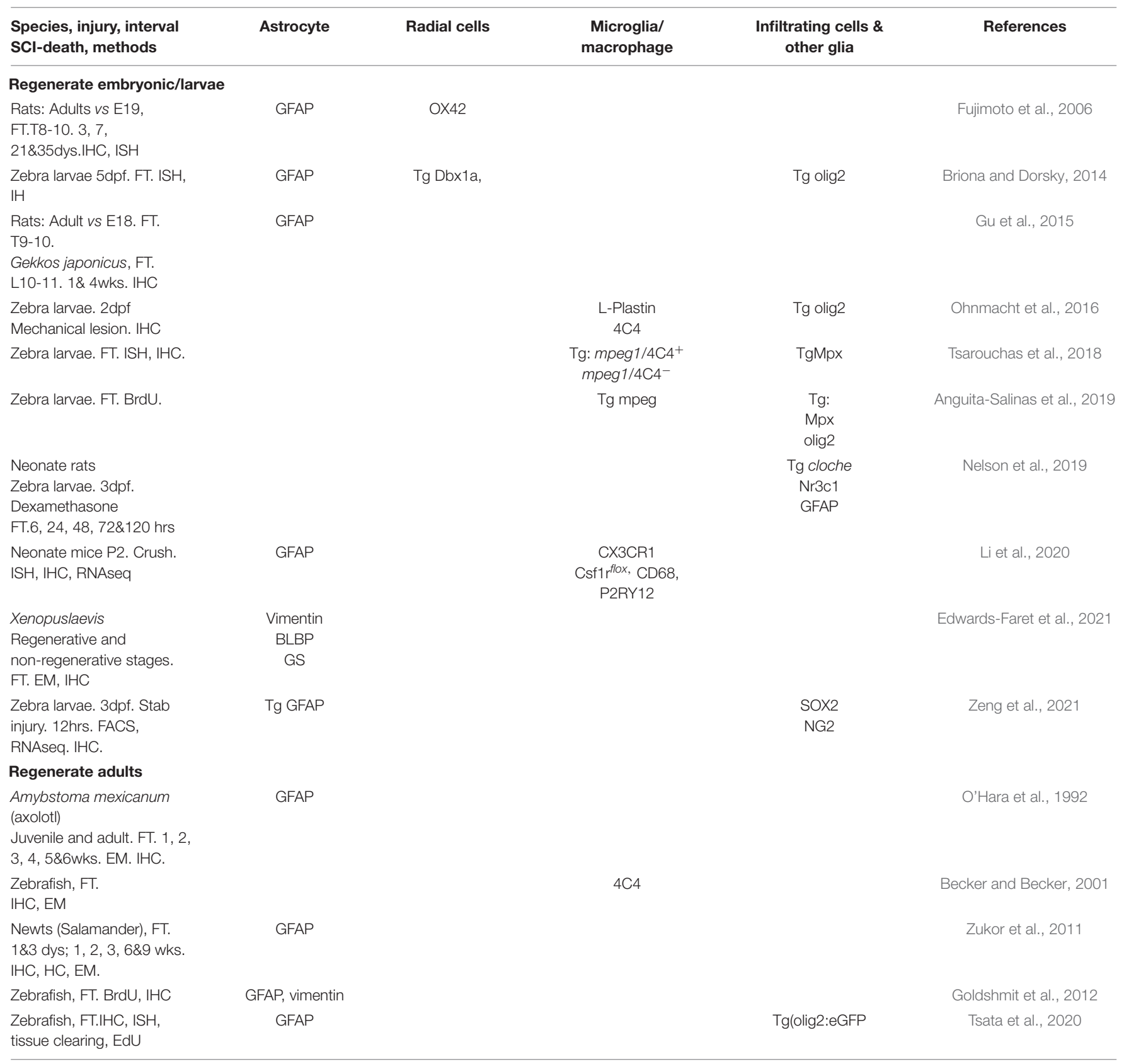

FACS, flow cytometry; hrs, hours; dys, days; wks, weeks; IHC, immunohistochemistry; T, thoracic; L, lumbar; FT, full transection; EM, electronic microscopy; ISH, in situ hybridisation; dpf, day post fertilisation; Tg, transgenic; E, embryonic.

the proliferation of ependymal glia. Remarkably, glucocorticoids directly inhibited the formation of trans-lesion glial bridges and prevented axon regrowth and functional recovery through activation of $\mathrm{Nr} 3 \mathrm{cl}$ signalling (Nelson et al., 2019). There is still debate as to whether the glial bridge is prerequisite to axonal regrowth or whether it forms concomitantly with regenerating axons (reviewed in Cigliola et al., 2020). Additionally, in the larval zebrafish, Dbxla-expressing cells that persist as radial glia and represent a pool of neurogenic progenitors can be activated in response to injury and differentiate into neurons
(Briona and Dorsky, 2014). In early developmental stages, radial glial cells displaying a bipolar shape are abundantly present in both mammals and salamanders. Following SCI in salamander, radial glia cells ligate both rostral- and caudal-sectioned ends of the spinal cord before proliferating and differentiating into other glial cells (including astrocytes and oligodendrocytes) and into neurons (reviewed in Tazaki et al., 2017). Along this line, in zebrafish embryos, stress-responsive regenerating cells that are induced by SCI and that play an essential role in axonal regeneration have been identified and further characterised as 
mostly composed of radial glia (Zeng et al., 2021). In contrast, upon SCI, radial glial cells of adult mammalians generate astrocytes. Instead of stretching to build an ependymal bridge, these astrocytes participate in the formation of a glial scar and prevent axonal regeneration. Further experiments to investigate the role of radial glia in neonatal mammals after SCI would certainly provide interesting findings to develop therapeutic strategies to favour axonal regeneration.

In both adult and larval zebrafish, the recruitment of immune cells has been observed after SCI. In adults, reactive microglia were observed at 2-3 days and at 14 days after spinal cord injury (Becker and Becker, 2001). In zebrafish larvae, recruitment of immune cells was observed as early as $2 \mathrm{~h}$ following the complete spinal cord section with a peak of neutrophils accumulation at the injury site (Tsarouchas et al., 2018). A slightly different time window of activation has also been reported after the complete spinal cord section, with a strong neutrophil recruitment until $12 \mathrm{~h}$ post injury at the lesion site, followed by its disappearance $24 \mathrm{~h}$ post injury (Anguita-Salinas et al., 2019). Macrophages and microglia were reported to be increased at $48 \mathrm{~h}$ post injury (Ohnmacht et al., 2016; Tsarouchas et al., 2018; AnguitaSalinas et al., 2019) and were detected next to the transection site at 7 and 42 days post lesion (Tsata et al., 2020). A brief, pro-inflammatory macrophage response, followed by an antiinflammatory state, was observed that may underlie rapid myelin debris clearance (reviewed in Ghosh and Hui, 2018) and has led to the hypothesis of a similarity between peripheral nervous system injury in mammals and CNS injury in zebrafish (Ghosh and Hui, 2018). Moreover, following the complete section of the adult zebrafish spinal cord, oligodendrocyte precursor cells survived, proliferated, and replaced lost oligodendrocytes that reestablished myelination (Tsata et al., 2020).

Comparison between regenerative (pre-metamorphosis stages) and non-regenerative (during metamorphosis) responses in Xenopus laevis highlighted that, in the same species, no glial scar was observed in regenerative stages conversely to the nonregenerative stage where a transient glial scar-like structure was formed (Edwards-Faret et al., 2021). Similarly, spinal crush injury in neonatal mice up to postnatal Day 2 led to scar-free healing, allowing axonal regrowth through the lesion (Li et al., 2020). When SCI occurred at 2 days post-natal (regenerative response), amoeboid activated microglia first accumulated in the stumps 2-3 dpi and quickly returned to a ramified "resting" morphology by 2 weeks post-injury, when spinal cord regeneration was complete. When SCI occurred after 7 days post-natal (the non-regenerative stage), microglia remained highly activated for at least 2 weeks. Moreover, RNA sequencing at 2 days post-natal highlighted that this transient microglial activation permitted the formation of a temporary fibronectin bridge that ligated the two ends of the spinal cord and allowed axon regeneration ( $\mathrm{Li}$ et al., 2020). Likewise, an intra-uterine complete section of the spinal cord at embryonic Day 19 in rats led to an absence of glial scar formation conversely to the same injury in adults (Fujimoto et al., 2006). Time course analysis showed an increase in the number of astrocytes and microglia/macrophages $\left(\mathrm{OX} 42^{+}\right)$in adults from 3 to 35 days after injury. Conversely, fetal injury led to a transient and rather limited increase in the number of astrocytes and microglia/macrophages at 3 and 3-7 days after injury, respectively. Additionally, leucocyte and macrophage infiltration were reported 3 and 7 days after SCI only in adults. In rodents, fetal and postnatal Day 2 injury thus led to a transient and limited activation of glial cells in the surrounding of the lesion contrariwise to SCI at the adult stage.

Comparative studies have been carried out in species, displaying high and low regenerative capabilities. One study characterised GFAP expression, following the complete spinal cord section in the adult gecko (Gekko japonicum), a reptile that displays a remarkable capacity for tail restoration, and adult rats. Concomitantly, astrocytic response was compared, following an in vitro scratch assay in adult geckos and rats and embryonic rats (Gu et al., 2015). In adult rats, GFAP expression was continuously increased from 1 to 4 weeks after SCI, while geckos displayed a transient expression peak at 1 week, followed by a decrease at 4 weeks. Moreover, astrocytes subjected to in vitro scratch wound displayed a higher GFAP expression and higher proliferative ability in adult rats than in embryonic rats and adult geckos. Lastly, it has been demonstrated, in zebrafish and rat, that the opposing regulation of the ependymal glial glucocorticoid receptor $(\mathrm{Nr} 3 \mathrm{cl})$, after complete spinal cord injury, participated in the differential responses between species (Nelson et al., 2019).

Taken together, these studies demonstrate that glial cells are present after spinal cord injury in non-mammal species and mammalian developmental stages that display spinal cord regeneration but respond differently as compared to the adult mammalian nervous system and seem to favour axon regeneration instead of hindering regrowth (Figure 3).

\section{CONCLUDING COMMENTS AND FUTURE DIRECTIONS}

Responses of glial and immune cells following spinal cord injury display similarities and differences across species that are strongly correlated with functional recovery. The overall dynamics of the glial response to SCI in adult rodents and primates, which present extremely limited tissue repair and functional recovery, is comparable across species. Indeed, at acute and subacute stages, an early activation of microglia/macrophages precedes immunecell infiltration and astrocyte activation (Figures 1A,B, 2A). Both microglia/macrophages and astrocytes proliferate and migrate toward the lesion site. At later stages, astrocytes form an astroglial barrier that surrounds the lesion core. Microglia and NG2 cells also constitute the stabilised scar with tight interlacing between all cell populations (soma and processes) (Figure 2B). The core of the lesion is composed of a fibrotic scar with monocyte-derived macrophages, infiltrating immune cells and a few activated microglia (Figure 2B).

Strikingly, temporal dynamics and levels of activation differ across species. In rodents, rats exhibit an earlier and monophasic infiltration of immune cells conversely to mice that display a delayed biphasic neutrophil and T cell infiltration (Figure 1A). Interestingly, in man, the peak number of neutrophils bears more similarity to mice than rats (Mawhinney et al., 2012). Another major difference is that cystic cavities are observed only (or at 
least predominantly) in rats and primates. Moreover, in primates, the astrocytic response is delayed and displays a lower level of activation as compared to rodents (Figure 1B).

The dynamics of the glial response to SCI is different in non-mammal species/mammalian developmental stages that exhibit high regenerative capacities and functional recovery. In particular, astroglial activation differs drastically, since astrocytes migrate toward the lesion site but form a bridge (Figure 3), and not a scar (Figure 2), which permits axonal regrowth through the lesion site. Interestingly, similar mechanisms are observed in embryonic and fetal mammals. The inflammatory response to SCI seems slightly different and leads to a faster myelin clearance that may resemble peripheral nervous system injury in adult mammals.

Recent findings have highlighted a sexual dimorphism in glial and immune cell responses present in pain signalling (for review, see Midavaine et al., 2021); thus, future investigations of the sex-dependent glial response and its crosstalk with immune cells, following SCI, are of great interest. The analysis of cellular dynamics following SCI in different contexts (species, age, sex, etc.) will help in the design of efficient therapeutic strategies used concomitantly, or sequentially, to improve recovery after CNS lesion.

\section{REFERENCES}

Anderson, M. A., Burda, J. E., Ren, Y., Ao, Y., O'shea, T. M., Kawaguchi, R., et al. (2016). Astrocyte scar formation aids central nervous system axon regeneration. Nature 532, 195-200. doi: 10.1038/nature17623

Anguita-Salinas, C., Sánchez, M., Morales, R. A., Ceci, M. L., Rojas-Benítez, D., and Allende, M. L. (2019). Cellular dynamics during spinal cord regeneration in larval zebrafish. Dev. Neurosci. 41, 112-122. doi: 10.1159/000500185

Beck, K. D., Nguyen, H. X., Galvan, M. D., Salazar, D. L., Woodruff, T. M., and Anderson, A. J. (2010). Quantitative analysis of cellular inflammation after traumatic spinal cord injury: evidence for a multiphasic inflammatory response in the acute to chronic environment. Brain 133, 433-447. doi: 10.1093/brain/ awp322

Becker, T., and Becker, C. G. (2001). Regenerating descending axons preferentially reroute to the gray matter in the presence of a general macrophage/microglial reaction caudal to a spinal transection in adult zebrafish. J. Comp. Neurol. 433, 131-147. doi: 10.1002/cne.1131

Bellver-Landete, V., Bretheau, F., Mailhot, B., Vallieres, N., Lessard, M., Janelle, M. E., et al. (2019). Microglia are an essential component of the neuroprotective scar that forms after spinal cord injury. Nat. Commun. 10:518. doi: 10.1038/ s41467-019-08446-0

Briona, L. K., and Dorsky, R. I. (2014). Radial glial progenitors repair the zebrafish spinal cord following transection. Exp. Neurol. 256, 81-92. doi: 10.1016/j. expneurol.2014.03.017

Buss, A., Brook, G. A., Kakulas, B., Martin, D., Franzen, R., Schoenen, J., et al. (2004). Gradual loss of myelin and formation of an astrocytic scar during Wallerian degeneration in the human spinal cord. Brain 127, 34-44. doi: 10.1093/brain/awh001

Camand, E., Morel, M. P., Faissner, A., Sotelo, C., and Dusart, I. (2004). Long-term changes in the molecular composition of the glial scar and progressive increase of serotoninergic fibre sprouting after hemisection of the mouse spinal cord. Eur. J. Neurosci. 20, 1161-1176. doi: 10.1111/j.1460-9568.2004.03558.x

Chang, H. T. (2007). Subacute human spinal cord contusion: few lymphocytes and many macrophages. Spinal Cord 45, 174-182. doi: 10.1038/sj.sc.3101910

Cigliola, V., Becker, C. J., and Poss, K. D. (2020). Building bridges, not walls: spinal cord regeneration in zebrafish. Dis. Model Mech. 13:dmm044131.

Courtine, G., Bunge, M. B., Fawcett, J. W., Grossman, R. G., Kaas, J. H., Lemon, R., et al. (2007). Can experiments in nonhuman primates expedite the translation

\section{AUTHOR CONTRIBUTIONS}

J-CP participated in the design of the review, analysed the data, and prepared the figures. YG contributed to the design of the review and the analysis of the data. FP conceptualised the design of the review, participated in the analysis and data interpretation, wrote the manuscript, and approved the final review. All authors contributed to the article and approved the submitted version.

\section{FUNDING}

This work was supported by the patient organisation "Verticale" (to YG and FP). The funding sources were not involved in study design, collection, analysis, and interpretation of the data as well as in the writing of the report and in the decision to submit the article for publication.

\section{ACKNOWLEDGMENTS}

We thank Ian Robbins for comments on the manuscript. Figures were created using BioRender.

of treatments for spinal cord injury in humans? Nat. Med. 13, 561-566. doi: $10.1038 / \mathrm{nm} 1595$

David, S., and Kroner, A. (2011). Repertoire of microglial and macrophage responses after spinal cord injury. Nat. Rev. Neurosci. 12, 388-399. doi: 10.1038/ nrn3053

David, S., Greenhalgh, A. D., and Kroner, A. (2015). Macrophage and microglial plasticity in the injured spinal cord. Neuroscience 307, 311-318. doi: 10.1016/j. neuroscience.2015.08.064

David, S., Kroner, A., Greenhalgh, A. D., Zarruk, J. G., and Lopez-Vales, R. (2018). Myeloid cell responses after spinal cord injury. J. Neuroimmunol. 321, 97-108. doi: 10.1016/j.jneuroim.2018.06.003

Dusart, I., and Schwab, M. E. (1994). Secondary cell death and the inflammatory reaction after dorsal hemisection of the rat spinal cord. Eur. J. Neurosci. 6, 712-724. doi: 10.1111/j.1460-9568.1994.tb00983.x

Edwards-Faret, G., González-Pinto, K., Cebrián-Silla, A., Peñailillo, J., GarcíaVerdugo, J. M., and Larraín, J. (2021). Cellular response to spinal cord injury in regenerative and non-regenerative stages in Xenopus laevis. Neural Dev. 16:2. doi: 10.1186/s13064-021-00152-2

Fan, H., Zhang, K., Shan, L., Kuang, F., Chen, K., Zhu, K., et al. (2016). Reactive astrocytes undergo M1 microglia/macrohpages-induced necroptosis in spinal cord injury. Mol. Neurodegener. 11:14.

Fleming, J. C., Norenberg, M. D., Ramsay, D. A., Dekaban, G. A., Marcillo, A. E., Saenz, A. D., et al. (2006). The cellular inflammatory response in human spinal cords after injury. Brain 129, 3249-3269. doi: 10.1093/brain/aw 1296

Fujimoto, Y., Yamasaki, T., Tanaka, N., Mochizuki, Y., Kajihara, H., Ikuta, Y., et al. (2006). Differential activation of astrocytes and microglia after spinal cord injury in the fetal rat. Eur. Spine J. 15, 223-233. doi: 10.1007/s00586-005-0 933-3

Ghosh, S., and Hui, S. P. (2018). Axonal regeneration in zebrafish spinal cord. Regeneration (Oxf) 5, 43-60.

Goldshmit, Y., Sztal, T. E., Jusuf, P. R., Hall, T. E., Nguyen-Chi, M., and Currie, P. D. (2012). Fgf-dependent glial cell bridges facilitate spinal cord regeneration in zebrafish. J. Neurosci. 32, 7477-7492. doi: 10.1523/JNEUROSCI.0758-12. 2012

Greenhalgh, A. D., and David, S. (2014). Differences in the phagocytic response of microglia and peripheral macrophages after spinal cord injury and its effects on cell death. J. Neurosci. 34, 6316-6322. doi: 10.1523/JNEUROSCI.4912-13.2014 
Greenhalgh, A. D., Zarruk, J. G., Healy, L. M., Baskar Jesudasan, S. J., Jhelum, P., Salmon, C. K., et al. (2018). Peripherally derived macrophages modulate microglial function to reduce inflammation after CNS injury. PLoS Biol. 16:e2005264. doi: 10.1371/journal.pbio.2005264

Gu, Y., Cheng, X., Huang, X., Yuan, Y., Qin, S., Tan, Z., et al. (2019). Conditional ablation of reactive astrocytes to dissect their roles in spinal cord injury and repair. Brain Behav. Immun. 80, 394-405. doi: 10.1016/j.bbi.2019.04.016

Gu, Y., Yang, J., Chen, H., Li, J., Xu, M., Hua, J., et al. (2015). Different astrocytic activation between Adult Gekko japonicus and rats during wound healing in vitro. PLoS One 10:e0127663. doi: 10.1371/journal.pone.0127663

Guest, J. D., Hiester, E. D., and Bunge, R. P. (2005). Demyelination and Schwann cell responses adjacent to injury epicenter cavities following chronic human spinal cord injury. Exp. Neurol. 192, 384-393. doi: 10.1016/j.expneurol.2004. 11.033

Hesp, Z. C., Yoseph, R. Y., Suzuki, R., Jukkola, P., Wilson, C., Nishiyama, A., et al. (2018). Proliferating NG2-cell-dependent angiogenesis and scar formation alter axon growth and functional recovery after spinal cord injury in mice. J. Neurosci. 38, 1366-1382. doi: 10.1523/JNEUROSCI.3953-16.2017

Iwanami, A., Yamane, J., Katoh, H., Nakamura, M., Momoshima, S., Ishii, H., et al. (2005). Establishment of graded spinal cord injury model in a nonhuman primate: the common marmoset. J. Neurosci. Res. 80, 172-181. doi: 10.1002/ jnr.20435

Kigerl, K. A., Gensel, J. C., Ankeny, D. P., Alexander, J. K., Donnelly, D. J., and Popovich, P. G. (2009). Identification of two distinct macrophage subsets with divergent effects causing either neurotoxicity or regeneration in the injured mouse spinal cord. J. Neurosci. 29, 13435-13444.

Kigerl, K. A., Mcgaughy, V. M., and Popovich, P. G. (2006). Comparative analysis of lesion development and intraspinal inflammation in four strains of mice following spinal contusion injury. J. Comp. Neurol. 494, 578-594. doi: 10.1002/ cne. 20827

Le Corre, M., Noristani, H. N., Mestre-Frances, N., Saint-Martin, G. P., Coillot, C., Goze-Bac, C., et al. (2018). A novel translational model of spinal cord injury in nonhuman primate. Neurotherapeutics 15, 751-769. doi: 10.1007/s13311-0170589-9

Li, X., Yang, B., Xiao, Z., Zhao, Y., Han, S., Yin, Y., et al. (2018). Comparison of subacute and chronic scar tissues after complete spinal cord transection. Exp. Neurol. 306, 132-137. doi: 10.1016/j.expneurol.2018.05.008

Li, Y., He, X., Kawaguchi, R., Zhang, Y., Wang, Q., Monavarfeshani, A., et al. (2020). Microglia-organized scar-free spinal cord repair in neonatal mice. Nature 587, 613-618. doi: 10.1038/s41586-020-2795-6

Liesi, P., and Kauppila, T. (2002). Induction of type IV collagen and other basement-membrane-associated proteins after spinal cord injury of the adult rat may participate in formation of the glial scar. Exp. Neurol. 173, 31-45. doi: 10.1006/exnr.2001.7800

Ma, Z., Zhang, Y. P., Liu, W., Yan, G., Li, Y., Shields, L. B. E., et al. (2016). A controlled spinal cord contusion for the rhesus macaque monkey. Exp. Neurol. 279, 261-273. doi: 10.1016/j.expneurol.2016.02.008

Mawhinney, L. A., Thawer, S. G., Lu, W. Y., Rooijen, N., Weaver, L. C., Brown, A., et al. (2012). Differential detection and distribution of microglial and hematogenous macrophage populations in the injured spinal cord of lys-EGFPki transgenic mice. J. Neuropathol. Exp. Neurol. 71, 180-197. doi: 10.1097/NEN. 0b013e3182479b41

McTigue, D. M., Tripathi, R., and Wei, P. (2006). NG2 colocalizes with axons and is expressed by a mixed cell population in spinal cord lesions. J. Neuropathol. Exp. Neurol. 65, 406-420. doi: 10.1097/01.jnen.0000218447.32320.52

Midavaine, E., Cote, J., Marchand, S., and Sarret, P. (2021). Glial and neuroimmune cell choreography in sexually dimorphic pain signaling. Neurosci. Biobehav. Rev. 125, 168-192. doi: 10.1016/j.neubiorev.2021.01.023

Miller, A. D., Westmoreland, S. V., Evangelous, N. R., Graham, A., Sledge, J., and Nesathurai, S. (2012). Acute traumatic spinal cord injury induces glial activation in the cynomolgus macaque (Macaca fascicularis). J. Med. Primatol. 41, 202-209. doi: 10.1111/j.1600-0684.2012.00542.x

Nelson, C. M., Lennon, V. A., Lee, H., Krug, R. G. II, Kamalova, A., Madigan, N. N., et al. (2019). Glucocorticoids target ependymal glia and inhibit repair of the injured spinal cord. Front. Cell Dev. Biol. 7:56. doi: 10.3389/fcell.2019.00056

Nishimura, S., Sasaki, T., Shimizu, A., Yoshida, K., Iwai, H., Koya, I., et al. (2014). Global gene expression analysis following spinal cord injury in non-human primates. Exp. Neurol. 261, 171-179. doi: 10.1016/j.expneurol.2014.05.021
Norenberg, M. D., Smith, J., and Marcillo, A. (2004). The pathology of human spinal cord injury: defining the problems. J. Neurotrauma 21, 429-440. doi: 10.1089/089771504323004575

Noristani, H. N., and Perrin, F. E. (2016). Astrocyte-to-neuron conversion induced by spinal cord injury. Oncotarget 7, 83831-83832. doi: 10.18632/oncotarget. 13780

Noristani, H. N., Gerber, Y. N., Sabourin, J.-C., Le Corre, M., Lonjon, N., MestreFrances, N., et al. (2017). RNA-Seq analysis of microglia reveals time-dependent activation of specific genetic programs following spinal cord injury. Front.n Mol. Neurosci. 10:90. doi: 10.3389/fnmol.2017.00090

Noristani, H. N., Sabourin, J. C., Boukhaddaoui, H., Chan-Seng, E., Gerber, Y. N., and Perrin, F. E. (2016). Spinal cord injury induces astroglial conversion towards neuronal lineage. Mol. Neurodegener. 11:68. doi: 10.1186/s13024-0160133-0

O'Hara, C. M., Egar, M. W., and Chernoff, E. A. (1992). Reorganization of the ependyma during axolotl spinal cord regeneration: changes in intermediate filament and fibronectin expression. Dev. Dyn. 193, 103-115. doi: 10.1002/aja. 1001930202

Ohnmacht, J., Yang, Y., Maurer, G. W., Barreiro-Iglesias, A., Tsarouchas, T. M., Wehner, D., et al. (2016). Spinal motor neurons are regenerated after mechanical lesion and genetic ablation in larval zebrafish. Development 143 , 1464-1474. doi: 10.1242/dev.129155

Pineau, I., and Lacroix, S. (2007). Proinflammatory cytokine synthesis in the injured mouse spinal cord: multiphasic expression pattern and identification of the cell types involved. J. Comp. Neurol. 500, 267-285. doi: 10.1002/cne.21149

Pineau, I., Sun, L., Bastien, D., and Lacroix, S. (2010). Astrocytes initiate inflammation in the injured mouse spinal cord by promoting the entry of neutrophils and inflammatory monocytes in an IL-1 receptor/MyD88dependent fashion. Brain Behav. Immun. 24, 540-553. doi: 10.1016/j.bbi.2009. 11.007

Popovich, P. G., Wei, P., and Stokes, B. T. (1997). Cellular inflammatory response after spinal cord injury in sprague-dawley and lewis rats. J. Comp. Neurol. 377, 443-464. doi: 10.1002/(sici)1096-9861(19970120)377:3\&lt;443::aid-cne10\&gt; 3.0.co;2-s

Poulen, G., Aloy, E., Bringuier, C. M., Mestre-Frances, N., Artus, E. V. F., Cardoso, M., et al. (2021). Inhibiting microglia proliferation after spinal cord injury improves recovery in mice and nonhuman primates. Theranostics $11,8640-$ 8659. doi: 10.7150/thno.61833

Poulen, G., and Perrin, F. E. (2018). Microcebus murinus: a novel promising nonhuman primate model of spinal cord injury. Neural Regen. Res. 13, 421-422. doi: 10.4103/1673-5374.228721

Pruss, H., Kopp, M. A., Brommer, B., Gatzemeier, N., Laginha, I., Dirnagl, U., et al. (2011). Non-resolving aspects of acute inflammation after spinal cord injury (SCI): indices and resolution plateau. Brain Pathol. 21, 652-660. doi: 10.1111/j.1750-3639.2011.00488.x

Puckett, W. R., Hiester, E. D., Norenberg, M. D., Marcillo, A. E., and Bunge, R. P. (1997). The astroglial response to Wallerian degeneration after spinal cord injury in humans. Exp. Neurol. 148, 424-432. doi: 10.1006/exnr.1997.6692

Ren, Y., Ao, Y., O’shea, T. M., Burda, J. E., Bernstein, A. M., Brumm, A. J., et al. (2017). Ependymal cell contribution to scar formation after spinal cord injury is minimal, local and dependent on direct ependymal injury. Sci. Rep. 7:41122. doi: $10.1038 /$ srep 41122

Sabelstrom, H., Stenudd, M., Reu, P., Dias, D. O., Elfineh, M., Zdunek, S., et al. (2013). Resident neural stem cells restrict tissue damage and neuronal loss after spinal cord injury in mice. Science 342, 637-640. doi: 10.1126/science.1242576

Shi, F., Zhu, H., Yang, S., Liu, Y., Feng, Y., Shi, J., et al. (2009). Glial response and myelin clearance in areas of wallerian degeneration after spinal cord hemisection in the monkey Macaca fascicularis. J. Neurotrauma 26, 2083-2096. doi: $10.1089 /$ neu.2008.0706

Slotkin, J. R., Pritchard, C. D., Luque, B., Ye, J., Layer, R. T., Lawrence, M. S., et al. (2017). Biodegradable scaffolds promote tissue remodeling and functional improvement in non-human primates with acute spinal cord injury. Biomaterials 123, 63-76. doi: 10.1016/j.biomaterials.2017.01.024

Sroga, J. M., Jones, T. B., Kigerl, K. A., Mcgaughy, V. M., and Popovich, P. G. (2003). Rats and mice exhibit distinct inflammatory reactions after spinal cord injury. J. Comp. Neurol. 462, 223-240. doi: 10.1002/cne.10736

Stirling, D. P., Cummins, K., Mishra, M., Teo, W., Yong, V. W., and Stys, P. (2014). Toll-like receptor 2-mediated alternative activation of microglia is 
protective after spinal cord injury. Brain 137, 707-723. doi: 10.1093/brain/aw $\mathrm{t} 341$

Tang, P., Zhang, Y., Chen, C., Ji, X., Ju, F., Liu, X., et al. (2015). In vivo two-photon imaging of axonal dieback, blood flow, and calcium influx with methylprednisolone therapy after spinal cord injury. Sci. Rep. 5:9691. doi: 10.1038/srep09691

Tazaki, A., Tanaka, E. M., and Fei, J. F. (2017). Salamander spinal cord regeneration: the ultimate positive control in vertebrate spinal cord regeneration. Dev. Biol. 432, 63-71. doi: 10.1016/j.ydbio.2017.09.034

Thuret, S., Thallmair, M., Horky, L. L., and Gage, F. H. (2012). Enhanced functional recovery in $\mathrm{MRL} / \mathrm{MpJ}$ mice after spinal cord dorsal hemisection. PLoS One 7:e30904. doi: 10.1371/journal.pone.0030904

Tsarouchas, T. M., Wehner, D., Cavone, L., Munir, T., Keatinge, M., Lambertus, M., et al. (2018). Dynamic control of proinflammatory cytokines Il-1beta and Tnf-alpha by macrophages in zebrafish spinal cord regeneration. Nat. Commun. 9:4670. doi: 10.1038/s41467-018-07036-w

Tsata, V., Kroehne, V., Wehner, D., Rost, F., Lange, C., Hoppe, C., et al. (2020). Reactive oligodendrocyte progenitor cells (re-)myelinate the regenerating zebrafish spinal cord. Development 147:dev193946. doi: 10.1242/dev.193946

Verkhratsky, A., Ho, M. S., and Parpura, V. (2019). Evolution of neuroglia. Adv. Exp. Med. Biol. 1175, 15-44. doi: 10.1007/978-981-13-9913-8_2

Wang, L., Hu, B., Wong, W. M., Lu, P., Wu, W., and Xu, X. M. (2009). Glial and axonal responses in areas of Wallerian degeneration of the corticospinal and dorsal ascending tracts after spinal cord dorsal funiculotomy. Neuropathology 29, 230-241. doi: 10.1111/j.1440-1789.2008.00969.x

Wanner, I. B., Anderson, M. A., Song, B., Levine, J., Fernandez, A., GrayThompson, Z., et al. (2013). Glial scar borders are formed by newly proliferated, elongated astrocytes that interact to corral inflammatory and fibrotic cells via STAT3-dependent mechanisms after spinal cord injury. J. Neurosci. 33, 12870-12886. doi: 10.1523/JNEUROSCI.2121-13.2013

White, R. E., Mctigue, D. M., and Jakeman, L. B. (2010). Regional heterogeneity in astrocyte responses following contusive spinal cord injury in mice. J. Comp. Neurol. 518, 1370-1390. doi: 10.1002/cne.22282

Wu, W., Wu, W., Zou, J., Shi, F., Yang, S., Liu, Y., et al. (2013). Axonal and glial responses to a mid-thoracic spinal cord hemisection in the Macaca fascicularis monkey. J. Neurotrauma 30, 826-839. doi: 10.1089/neu.2012.2681

Yang, L., Blumbergs, P. C., Jones, N. R., Manavis, J., Sarvestani, G. T., and Ghabriel, M. N. (2004). Early expression and cellular localization of proinflammatory cytokines interleukin-1beta, interleukin-6, and tumor necrosis factor-alpha in human traumatic spinal cord injury. Spine (Phila Pa 1976) 29, 966-971. doi: 10.1097/00007632-200405010-00004

Yang, T., Dai, Y., Chen, G., and Cui, S. (2020). Dissecting the dual role of the glial scar and scar-forming astrocytes in spinal cord injury. Front. Cell Neurosci. 14:78. doi: 10.3389/fncel.2020.0 0078

Zai, L. J., and Wrathall, J. R. (2005). Cell proliferation and replacement following contusive spinal cord injury. Glia 50, 247-257.

Zeng, C. W., Kamei, Y., Shigenobu, S., Sheu, J. C., and Tsai, H. J. (2021). Injury-induced Cavl-expressing cells at lesion rostral side play major roles in spinal cord regeneration. Open Biol. 11:200304. doi: 10.1098/rsob.20 0304

Zhu, Y., Lyapichev, K., Lee, D. H., Motti, D., Ferraro, N. M., Zhang, Y., et al. (2017). Macrophage transcriptional profile identifies lipid catabolic pathways that can be therapeutically targeted after spinal cord injury. J. Neurosci. 37, 2362-2376. doi: 10.1523/JNEUROSCI.2751-16.2017

Zhu, Y., Soderblom, C., Krishnan, V., Ashbaugh, J., Bethea, J. R., and Lee, J. K. (2015a). Hematogenous macrophage depletion reduces the fibrotic scar and increases axonal growth after spinal cord injury. Neurobiol. Dis. 74, 114-125. doi: 10.1016/j.nbd.2014.10.024

Zhu, Y., Soderblom, C., Trojanowsky, M., Lee, D. H., and Lee, J. K. (2015b). Fibronectin matrix assembly after spinal cord injury. J. Neurotrauma 32, 11581167. doi: 10.1089/neu.2014.3703

Zrzavy, T., Schwaiger, C., Wimmer, I., Berger, T., Bauer, J., Butovsky, O., et al. (2021). Acute and non-resolving inflammation associate with oxidative injury after human spinal cord injury. Brain 144, 144-161. doi: 10.1093/brain/ awaa360

Zukor, K. A., Kent, D. T., and Odelberg, S. J. (2011). Meningeal cells and glia establish a permissive environment for axon regeneration after spinal cord injury in newts. Neural Dev. 6:1. doi: 10.1186/1749-8104-6-1

Conflict of Interest: The authors declare that the research was conducted in the absence of any commercial or financial relationships that could be construed as a potential conflict of interest.

Publisher's Note: All claims expressed in this article are solely those of the authors and do not necessarily represent those of their affiliated organizations, or those of the publisher, the editors and the reviewers. Any product that may be evaluated in this article, or claim that may be made by its manufacturer, is not guaranteed or endorsed by the publisher.

Copyright (c) 2021 Perez, Gerber and Perrin. This is an open-access article distributed under the terms of the Creative Commons Attribution License (CC BY). The use, distribution or reproduction in other forums is permitted, provided the original author(s) and the copyright owner(s) are credited and that the original publication in this journal is cited, in accordance with accepted academic practice. No use, distribution or reproduction is permitted which does not comply with these terms. 